\title{
Л.И. Дворецкий
}

ФГБОУ ВО Первый Московский Государственный Медицинский Университет им. И.М. Сеченова, кафедра госпитальной терапии № 2, Москва, Россия

\section{ПУТЕШЕСТВИЕ В СТРАНУ ЯТРОГЕНИЯ (Сообщение 2)}

\section{L.I. Dvoretsky}

I.M. Sechenov First Moscow State Medical University, Faculty of Medicine, Chair of Internal Medicine № 2, Moscow, Russia

\section{TRAVEL TO COUNTRY IATROGENIC (Message 2)}

\begin{abstract}
Резюме
Проблема ятрогении неизбежно диктует необходимость не только исчерпывающего определения (что в принципе невозможно), но и классификации с разделением на различные виды. В статье рассматриваются основные виды ятрогений, приводятся и анализируются классификации ятрогений, предложенные И.А. Кассирским, Е.М. Тареевым, С.Я. Долецким, А.В. Смольянниковым, В.В. Некачаловым и др., в основу которых положены различные принципы и подходы. С учетом расширенной трактовки ятрогений и необходимости мультидисциплинарного подхода к данной проблеме среди ятрогенных событий, предложено выделять следующие виды ятрогений: психогенные, госпитальные, лечебно-профилактические, ятрогении диагностических исследований.

Особое внимание в статье уделено психогенным ятрогениям, нередко возникающим в процессе общения врача и больным. Рассматриваются не только ятрогении, «имеющие исходным пунктом поведение врача», но и ятрогении, вызванные определёнными чертами характера больного (неуверенность, склонность к тревожным опасениям, повышенное внимание к малейшим изменениям самочувствия, эмоциональная ранимость и др.), предопределяющие неадекватные реакции на любую получаемую им медицинскую информацию. Немаловажное значение в развитии психогенных ятрогений приобретает качество медицинской документации, выдаваемой врачом пациенту (выписки из историй болезни, консультативные заключения, описания результатов исследований, рекомендации и др.). При этом следует избегать формулировок, которые без должного объяснения могут быть неадекватно восприняты больным и насторожить его. К источникам психогенных ятрогений некоторые авторы относят также неправильно проводимое медицинское просвещение, публикации спорных, не имеющих научного обоснования результатов, не отвечающих требованиям доказательной медицины, хотя врач может и не принимать в этом непосредственного участия. Автор статьи призывает коллег более внимательно относиться к процессу общения с пациентом, подготовке документации в процессе ведения пациентов, помнить о том, что психогенные ятрогении могут иметь негативные последствия для больного, быть источником нарушения взаимоотношений между врачом и пациентом.
\end{abstract}

Ключевые слова: ятрогения, психогения, психогенные ятрогении

Для цитИрования: Дворецкий Л.И. ПУТЕШЕСТВИЕ В СТРАНУ ЯТРОГЕНИЯ (Сообщение 2). Архивъ внутренней медицины. $2017 ;$ 7(3): 165-170. DOI: $10.20514 / 2226-6704-2017-7-3-165-170$

\begin{abstract}
The problem of iatrogenesis inevitably dictates the need for not only an exhaustive definition (which in principle is impossible), but also classification with a division into different species. The article deals with the main types of iatrogenia, the classification of iatrogenic proposed by I.A. Kassirsky, E.M. Tareev, S.Ya. Doletsky, A.V. Smolyannikov, V.V. Nekatchalov, and others, which are based on various principles and approaches. Given the expanded interpretation of iatrogenic and the need for a multidisciplinary approach to this problem among iatrogenic events, it is suggested to distinguish the following types of iatrogenic: psychogenic, hospital, therapeutic and preventive, iatrogenic diagnostic studies.

Particular attention is paid in the article to psychogenic iatrogenia, which often arises in the process of communication between a doctor and patients. They consider not only iatrogenia, «having a starting point for the behavior of a doctor», but also iatrogenia, caused by certain traits of the patient's character (insecurity, propensity to anxiety fears, increased attention to the slightest changes in health, emotional vulnerability, etc.), pred etermining inadequate reactions to any Medical information.

Of no small importance in the development of psychogenic iatrogenia is the quality of the medical documentation issued by the doctor to the patient (extracts from the case histories, advisory opinions, descriptions of research results, recommendations, etc.)

In this case, it is necessary to avoid formulations that, without proper explanation, may be inadequately perceived by the patient and alert him or her. To the sources of psychogenic iatrogenic, some authors also refer to improperly conducted medical education, the publication of contentious, nonscientific results that do not meet the requirements of evidence-based medicine, although the doctor may not directly participate in this.
\end{abstract}

*Контакты/Contacts. E-mail: dvoretski@mail.ru 
The author of the article encourages colleagues to pay more attention to the process of communication with the patient, the preparation of documentation in the process of patient management, to remember that psychogenic iatrogenia can have negative consequences for the patient, and can be a source of violation of the relationship between the doctor and the patient.

Key words: iatrogenia, psychogeny, psychogenic iatrogenia

For citation: Dvoretsky L.I. TRAVEL TO COUNTRY IATROGENIC (Message 2). Archive of internal medicine. 2017; 7(3): 165-170. [In Russian]. DOI: 10.20514/2226-6704-2017-7-3-165-170

DOI: 10.20514/2226-6704-2017-7-3-165-170

Проблема ятрогении неизбежно диктует необходимость не только исчерпывающего определения (что в принципе невозможно), но и классификации с разделением на различные виды. В настоящее время предложены многочисленные классификации ятрогений, в основе которых лежат различные принципЫ и пОдХОдЫ.

\section{Основные виды ятрогений}

Долгое время после публикации статьи доктора Освальда Бумке «Врач, как причина душевных расстройств» [1], ятрогения рассматривалась в рамках психогений. Однако по мере расширения диагностических возможностей, использования инвазивных методов, пополнения арсенала лекарственных средств, увеличения хирургической активности термин ятрогения стал трактоваться более широко.

Впервые расширил понятие ятрогении известный русский интернист ХХ века И.А. Кассирский (рис. 1), охарактеризовавший ее как «болезни функциональные и органические», непосредственной причиной которых являются действия врача. Согласно

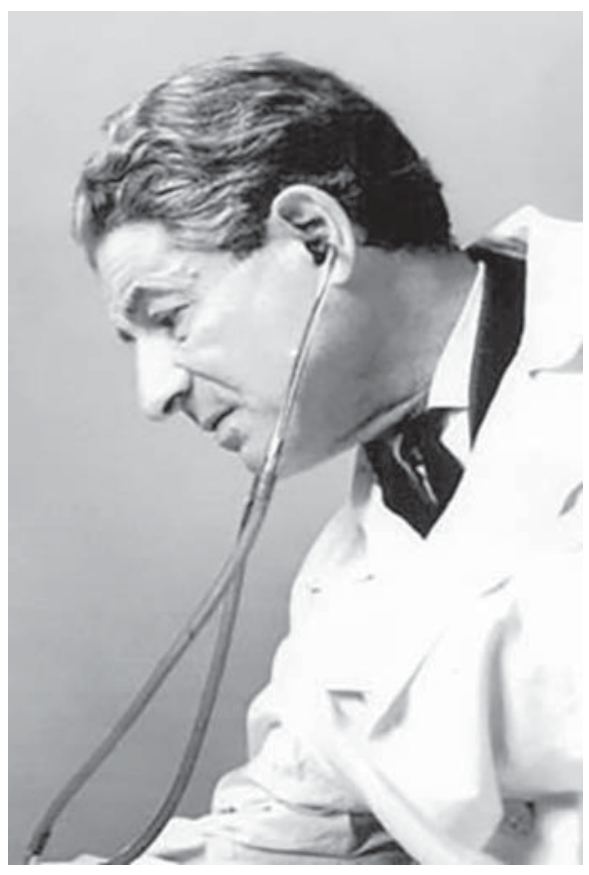

Рисунок 1. Иосиф Абрамович Кассирский (1898-1971)

Figure 1. Joseph Abramovich Kassirsky (1898-1971)
И.А. Кассирскому, существуют следующие формы ятрогений в зависимости от причин их развития:

- прямое травмирование больного неумелым подходом врача, медицинского персонала;

- непрямое травмирование, связанное с чтением медицинской литературы;

- ятрогенное заболевание, в основном связанное с личностными свойствами пациента, склонного к психопатическим, психастеническим, навязчивым реакциям;

- неправильное проведение врачом инструментального исследования, ошибочное введение лекарств;

- форма ятрогении, когда даже успешное лечение какого-либо заболевания специалистом того или иного профиля влечет за собой возникновение Аругого заболевания, требующего компетенции врача другой специальности [2].

Рубрика «непрямое травмирование, связанное с чтением медицинской литературы) по современным представлениям не является истинной ятрогенией, поскольку исключает непосредственный контакт врача и пациента. Чтение медицинской литературы пациентами и трактовка ими прочитанного это личная инициатива самих пациентов, как и их тревога за свое здоровье, источником которой стали средства массовой информации.

Основными причинами ятрогений И.А. Кассирский считал диагностические исследования и лекарственное лечение, в результате ошибочного, по его мнению, назначения, не исключая, впрочем, и возможности возникновения ятрогений оттого, что врачи не владеют методами психотерапии и психопрофилактики, не умея (не ушибить больного ненужной правдой о болезним [2].

Аругой российский интернист, академик Е.M. Тареев (рис. 2), внесший большой вклад в изучение ятрогений, прозорливо заметил, что (проблема ятрогенных болезней, буквально - болезней, порожденных врачом, является острой, неотложной, принципиальной, теоретической и сугубо практической, высокоответственной злободневной темой) [доклад на 4 Всесоюзном съезде терапевтов, 1978 год]. Е.М. Тареев рассматривал ятрогению как многогранное проявление врачебной деятельности - (теневую сторону больничного лечения, большой лекарственной терапии во что бы то ни стало, как результат, в том числе и агрессивности, многих диагностических и лечебных процедур» [3]. 
Вслед за интернистами на проблему ятрогении было обращено внимание хирургов, предлагавших свои классификации. В 1989 г. в Центральном институте усовершенствования врачей известный детский хирург, член-корреспондент РАМН С.Я. Аолецкий, заведующий кафедрой детских болезней, прочитал лекцию (Ятрогении), в которой дал следующее определение: «Ятрогения - неумышленный и зачастую неизбежный вред, наносимый пациенту вследствие общения с ним или воздействия на него, а также в результате бездействий медицинского персонала при профилактических и лечебных мероприятиях... Ятрогению целесообразно рассматривать в двух значениях: первое - ятрогению воздействия в соответствии с принятым ВОЗ понятием о нанесении вреда пациенту при профилактических диагностических и лечебных процедурах; второе - ятрогению общения, которая является составной частью понятия “деонтология). Подобный подход позволит в процессе обучения и критического анализа работы врача четко разграничить обе стороны ятрогении).

С.Я. Аолецкий, ставший в силу своей специальности свидетелем ятрогенных событий, нередко трагических, у наиболее уязвимого и незащищенного контингента, детей, предложил выделить следующие виды ятрогений [4]:

- ятрогения от общения, является составной часть деонтологии;

- алиментарная, возникающая в результате нерациональное питание больных и, как следствие, развитие или возникновение болезней от нерационального питания;

- медикаментозная - возникает наиболее часто и может выражаться в побочном действии лекарственных средств: от аллергических реакций и шока до медикаментозных язв ЖКТ и кровотечений из него;

- манипуляционная, обусловленная обилием инвазивных диагностических методов диагностики и приемов: биопсии, эндоскопии;

- наркозно-реанимационная - это все осложнения, которые возникают или регистрируются в этой области медицины: остановка сердца, дыхания, повреждение мозга и т.д.;

- хирургическая - в ней концентрируются все сложные и самые трагические проявления ятрогений;

- лучевая - патологическое воздействие на организм при повышении дозировок лучей рентгена, радиоизотопов, лазерного излучения.

В классификации, предложенной С.Я. Аолецким [4], очевидна тенденция рассматривать ятрогении как "разнообразие негативных моментов в процессе контакта врача или медицинского персонала с больным) (вербальный контакт, назначение диагностических исследований, лекарственной и лучевой терапии, хирургические операции и т.А.).

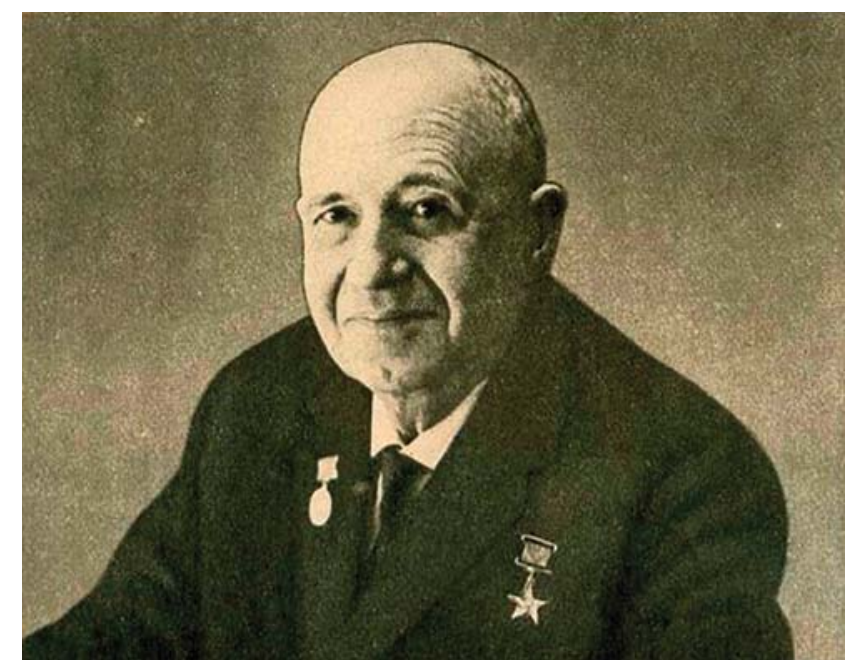

Рисунок 2. Евгений Михайлович Тареев (1895-1986) Figure 2. Evgeniy Mikhailovich Tareyev (1895-1986)

По мнению А.В. Смольянникова и соавт. [1995], ятрогения может возникнуть не только под влиянием состоявшегося медицинского воздействия, необходимого при лечении больного, но и в результате лечебнодиагностической пассивности врача, что равнозначно неоказанию необходимой врачебной помощи.

Наиболее полной в нашей стране на сегодня является рубрикация ятрогений, предложенная В.В. Некачаловым [1990]. Ятрогении, по его мнению,- это заболевания, патологические процессы, состояния, необычные реакции, возникновение которых однозначно обусловлено медицинским воздействием в ходе обследования, лечения больных, выполнения диагностических и профилактических процедур. Автор предложил рубрикацию ятрогенных заболеваний, включающую 12 рубрик. Аоминирующими оказались хирургические (36,3%), инфекционно-септические $(25,0 \%)$ и медикаментозные $(17,2 \%)$ ятрогении. В.В. Некачалов также выделил инструментально-диагностические (7,7 \%), трансфузионно-инфузионные (5,9 \%), наркозно-анестезиологические (4,7 \%) и лучевые (2,9 \%) ятрогении, ятрогении, связанные с применением неисправных технических средств аппаратов и приборов: реанимационные, профилактические, информационные и прочие ятрогении [5].

Подобная позиция находится в соответствии с Международной статистической классификацией болезней и проблем, связанных со здоровьем) 10го пересмотра (МКБ-10) где в отношении ятрогений имеются следующие толкования и рубрикации: (Ятрогениями следует считать неблагоприятные последствия лечебных и диагностических мероприятий. Они включают в себя неблагоприятные результаты лечебных мероприятий, проведенных по ошибочному диагнозу или с косметической целью, неправильно проведенные лечебные мероприятия, послужившие причиной инвалидизации или смерти 
больного, случайное нанесение вреда больному в ходе плановой хирургической операции, переливание иногруппной крови, манипуляции, проведенные с диагностической целью, осложнения лекарственной терапии с развитием дисбактериоза, экзои эндогенной суперинфекции, а также смертельные аллергические реакции и смерть от наркоза».

Также, «к группе ятрогенных последствий можно относить или случайное нанесение вреда больному вследствие медицинского вмешательства (невмешательства) в результате тактических или технических ошибок, или осложнение, не являющееся следствием неправильных действий, или аномальную реакцию организма на медицинское воздействие». При этом МКБ-10, к сожалению, тоже не дает окончательного ответа на вопрос, как на практике дифференцировать ятрогенный и неятрогенный процессы.

Ряд авторов [6] предлагает включать в число ятрогений и некоторые случаи расхождений прижизненного и посмертного диагнозов, а также случаи поздней диагностики, если они повлияли на исход заболевания.

В настоящее время с учетом расширенной трактовки ятрогений и необходимости мультидисциплинарного подхода к данной проблеме среди ятрогенных событий, на наш взгляд, следует выделять следующие виды ятрогений: психогенные, госпитальные, лечебно-профилактические, ятрогении диагностических исследований. Разумеется, что подобное разделение условно, поскольку каждая из ятрогений может быть взаимообусловленной или сочетаться друг с другом.

\section{Психогенные ятрогении}

Спустя полвека после публикации О. Бумке российский терапевт Р.А. Аурия (рис. 3) в своей монографии «Внутренняя картина болезней и иатрогенные заболевания), отстаивая взгляд немецкого психиатра на ятрогении, указывал, что «...ятрогения носит чисто психологический характер и является прямым или косвенным результатом внушения врача всегда помимо воли или даже помимо сознания больного» [7]. По его мнению ятрогении - болезни, (имеющие исходным пунктом поведение врача). Вот что называл Р.А. Аурия (внутренней картиной болезни): (...Внутренней же картиной болезни я называю все то, что испытывает и переживает больной, всю массу его ощущений, не только местных болезненных, но его общее самочувствие, самонаблюдение, его представления о своей болезни, о ее причинах, все то, что связано для больного с приходом его к врачу, - весь тот огромный внутренний мир больного, который состоит из весьма сложных сочетаний восприятия и ощущения, эмоций, аффектов, конфликтов, психических переживаний и травм» [7].
С целью предотвращения ятрогений Р.А. Аурия призывал врачей (...соблюсти психическую асептику), на что обращали внимание и другие клиницисты $[2,8,9]$. Следует указать, что задолго до упоминавшихся авторов один из основоположников русской внутренней медицины М.Я. Мудров, считавшийся лучшим русским терапевтом первой четверти XIX века и впервые предложивший анамнестический метод обследования больного, писал: “...врач посредственный более опасен, нежели полезен. Больные, оставленные натуре, выздоравливают, а использованные этими врачами мрут) [Мудров М.Я. БМЭ. М., 1981; 15: 1682-1686].

В формировании психогенной ятрогении, помимо неосторожных, ранящих пациента высказываний врача о его состоянии здоровья, могут играть роль также определённые черты характера больного (неуверенность, склонность к тревожным опасениям, повышенное внимание к малейшим изменениям самочувствия, эмоциональная ранимость и др.), предопределяющие неадекватные реакции на любую получаемую им медицинскую информацию. Такие пациенты требуют особой тактики в общении с ними, поскольку именно у них велика вероятность формирования навязчивых страхов за свое здоровье, настороженного отношения к врачебным назначениям и рекомендациям, что в итоге, может способствовать формированию психогенной ятрогении. Некоторые специалисты даже считают, что в подобных ситуациях следует говорить о псевдоятрогении, поскольку она возникает не столько по вине врача, сколько вследствие особенностей характера пациентов, склонных к навязчивым страхам за своё здоровье без серьёзных на то оснований. Тем не менее, роль врача в развитии подобного рода психогенных тревожных расстройств остается ведущей.

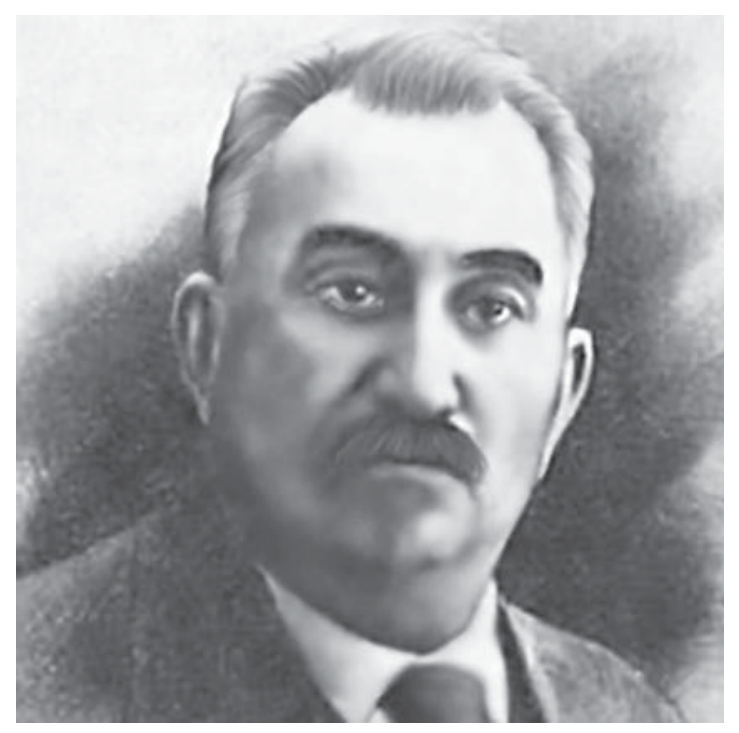

Рисунок 3. Роман Альбертович Аурия (1874-1944) Figure 3. Roman Albertovich Luria (1874-1944) 
Обсуждая проблему психогенных ятрогений, необходимо, прежде всего, указать, что в процессе общения врача с больными всемогущее значение приобретает слово. Будучи одним из чудеснейших исцелителей, слово врача при неправильном его использовании может превратиться в орудие, губящее больного. Такое специфическое значение слова для человека, а тем более - для больного человека, призывает врача к исключительно осторожному, продуманному, бережному пользованию им.

Авиценна утверждал, что у врача три оружия: слово, лекарство и нож. Спустя несколько веков именно эти три медицинских орудия - слово, лекарства и нож продолжают оставаться основными источниками ятрогений. Потребность в слове объединяет врачей с писателями. Неумение врача владеть словом может стать одним из факторов возникновения у пациента ятрогенных нарушений. В качестве возникновения психогенной ятрогении с фатальным исходом может служить случай из практики известного русского интерниста, профессора Б.Е. Вотчала (рис. 4). Во время одного из обходов в палате Б.Е. Вотчал, осматривавший больного, находящегося в клинике по поводу инфаркта миокарда и готовящегося к выписке, заметил, что его не следует выписывать, так как ему не нравятся тоны сердца. Больной был оставлен в клинике, а ночью он скончался от повторного инфаркта миокарда. Наутро больной, находившийся рядом с умершим, рассказал профессору, что тот очень расстроился после обхода, был обеспокоен и говорил: (Когда я сам чувствовал, что умираю, приходил Борис Евгеньевич и ему всегда нравились тоны моего сердца. Если даже сейчас они ему не нравятся - мои дела плохи). Б.Е. Вотчал тяжело переживал случившееся и говорил: (этот случай я не могу забыть 20 лет, и он мне служит постоянным напоминанием о том, как и с какой осторожностью, приходится применять у постели тяжелого больного, каждое слово - этот чрезвычайный раздражитель) [10].

Курьезный и вместе с тем трагический случай приводит из своей практики один патологоанатом. Женщина страдала ишемической болезнью сердца, что, естественно, беспокоило ее как физически, так и психологически. Чтобы как-то успокоить свою пациентку, лечащий врач, решив (Подбодрить) ее, сказал, что все будет хорошо, и что она раныше него самого не умрет. По роковой случайности, лечащий доктор умер на следующий день от внутримозгового кровоизлияния, а пациентка, узнав о его смерти, скончалась через несколько дней от инфаркта миокарда. Подобных примеров может быть приведено великое множество. Поэтому задачей врача является осторожное, продуманное, целенаправленное обращение со словом, тем более, когда больной (уходит) в болезнь, живет (эмоциями ожидания), когда у больного чередуются чувства доверия, надежды и страха, неуверенности. Главная цель беседы врача с больным - не толь-

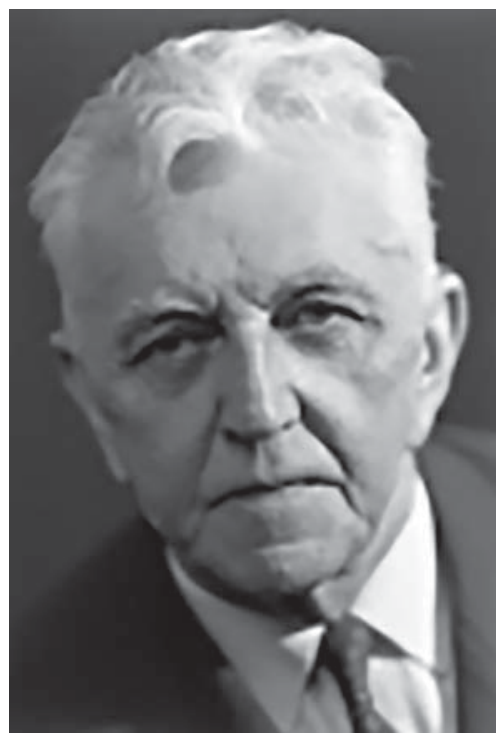

Рисунок 4. Борис Евгеньевич Вопчал (1895-1971)

Figure 4. Boris Evgenievich Votchal (1895-1971)

ко получение максимальной информации о течении заболевания и психическом состоянии пациента, но и создание максимально благоприятных условий для ведения - диагностических манипуляций, лечения, предупреждения эмоциональных осложнений и т.д.

Слово врача, пожалуй, самый главный врачебный инструмент при общении с определенной категорией пациентов, страдающих невротическими расстройствами и не всегда имеющих показания для назначения медикаментозной терапии. При этом умение владеть словом и силой убеждения для таких пациентов гораздо более существенно, чем назначение лекарственного препарата, отвечающего принципам доказательной медицины. Именно в подобных ситуациях становится очевидным и лишний раз приходится убеждаться, что профессия врача является (говорящей).

Вот что пишет о значении слова для больного Стефан Цвейг в очерке (Врачевание и психика): (Но того, кто знает, какие чудеса может совершать Аогос, творческое слово, это чародейное сотрясение уст в пустоте, создавшее бесчисленные миры и бесчисленные миры разрушившее, того не поразит, что в науке врачевания, как и во всех других областях, несчетное число раз совершались при посредстве единого слова истинные чудеса, что только через словесное обращение и взгляд - этих посланцев от личности к личности во многих случаях могло быть восстановлено, исключительным воздействием на дух, здоровье в организмах совершенно расшатанных...); (...в этом призыве к больному - воспрянуть душою, собрать воедино свою волю и целостность своего существа противопоставить целостности болезни - и состоит существеннейшее и единственное врачебное средство всех психических методов, и пособничество их пред- 
ставителей ограничивается по большей части не чем либо иным, как такого рода словесным обращением).

Слово, как наиболее совершенное средство общения между людьми, несет в себе не только частное, конкретное содержание, но и точно передает все сложные обстоятельства жизни в их иногда неотвратимом отношении к больному. Качество собранного анамнеза (история настоящего заболевания) во многом определяется умением употребить нужные слова, в нужном сочетании, для нужной цели, с нужным подходом к больному. В зависимости от качества и формулировки вопросов можно получить соответствующий ответ. Приверженность врача к слову отражает его потребность в выражения своих эмоций, отношения к больному. Это важно для получения максимально исчерпывающих сведений и информации о характере и течении заболевании, о психологическом типе пациента, о его отношении к своей болезни. Врач должен обязательно подобрать нужные слова как для больного, так и для его близких, каждый из которых ждет от врача не только информации о болезни и способах лечения, но и оценки прогноза больного.

Искусство слова - прекрасное, умное, доброе способно вызвать не только целый ряд душевных переворотов в человеке, но и оказать благотворное воздействие на настроение и мысли больного. Эти особенности воздействия многих литературных произведений на психику человека с успехом используют в практической медицине. Аечение с помощью книг получило название библиотерапии.

Немаловажное значение в развитии психогенных ятрогений приобретает качество медицинской документации, выдаваемой врачом пациенту (выписки из историй болезни, консультативные заключения, описания результатов исследований, рекомендации и др.). При этом следует избегать формулировок, которые без должного объяснения могут быть неадекватно восприняты больным и насторожить его. Классический пример такой психогенной ятрогении приводит все тот же Р.А. Аурия [7]. Одному больному была нанесена психическая травма заключением рентгенолога о том, что у него «луковица двенадцатиперстной кишки плохо отшнуровывается). Этот привычный для рентгенолога термин вызвал настоящую панику у больного. “Что будет - тревожился больной, - если она вообще отшнуруется?» С такой психогенной травмой удалось справиться с трудом и не сразу. Врач должен изложить свои впечатления и мысли о характере и течении заболевания на бумаге, что у каждого получается по-разному. К источникам психогенных ятрогений некоторые авторы относят также неправильно проводимое медицинское просвещение, публикации спорных, не имеющих научного обоснования результатов, не отвечающих требованиям доказательной медицины, хотя врач может и не принимать в этом непосредственного участия.
Несмотря на наличие современных компьютеров, совершенных диагностических приборов, новейших лекарств с самым широким спектром действия и многое другое, ошибки в профессиональном поведении медицинских работников, очевидно, еще не скоро исчезнут. Быть может, они не исчезнут никогда. Самое главное для врача - не пытаться их скрыть, переложить на чьи-либо плечи. Необходимо отыскать причину, породившую ошибку, и принять все меры для того, чтобы не допускать подобного в дальнейшем.

\section{Конфликт интересов/Conflict of interests}

Авторы заявляют, что данная работа, её тема, предмет и содержание не затрагивают конкурирующих интересов/The authors state that this work, its theme, subject and content do not affect competing interests

\section{Список литературы / References:}

1. Bumke O. Der Arzt als Ursache seelischer Störungen. Deutsche Medizinische Wochenschrift, 1925; 51(1): 3.

2. Кассирский И.А. Об иатрогенных заболеваниях. Труды I Всесоюзной конференции по проблеме медицинской деонтологии М., 1970; 55-64.

Kassirsky I.A. About iatrogenic diseases. Proceedings of the First AllUnion Conference on the Problem of Medical Deontology. M., 1970; 55-64 [In Russian].

3. Тареев Е.М. Ятрогенные болезни. Терапевтический архив. 1978; 50(1): 3-12.

Tareev E.M. latrogenic diseases. Therapeutic archive. 1978; 50 (1): 3-12 [In Russian].

4. Долецкий С.Я. Ятрогения в хирургии. Ятрогенные болезни и повреждения: С6. науч. работ. Махачкала, 1991; 14-18.

Doletsky S.Ya. Yatrogeny in surgery. latrogenic diseases and injuries: Collection of scientific works. Makhachkala, 1991; 14-18 [In Russian].

5. Некачалов В.В. Ятрогении (Патология диагностики и лечения). СПб. Практическое пособие. М., 1998.

Nekachalov V.V. Yatrogenii (pathology of diagnosis and treatment). St. Petersburg. Practical manual. M., 1998 [In Russian].

6. Каминский Ю.В, Непрокина И.В. Тихоокеанский мед. журн. 2002; 3: 18-21.

Kaminsky Yu.V., Neprokina IV Pacific Medical Journal. 2002; 3: 18-21 [In Russian].

7. Лурия Р.А. Внутренняя картина болезней и иатрогенные заболевания. М., 1977.

Luria R.A. Internal picture of diseases and iatrogenic diseases. M., 1977 [In Russian].

8. Вайль С.С. Некоторые вопросы врачебной деонтологии. Л., 1969. Weil S.S. Some questions of medical deontology. L., 1969 [In Russian].

9. Эльштейн Н.В. Ятрогенные заболевания. БМЭ. М., 1986; 15921596.

Elstein N.V. Iatrogenic diseases. BME. M., 1986; 1592-1596 [In Russian].

10. Северова Е.Я. Ятрогения. Советская медицина. 1980; 7: 3-7. Severova E.Ya. latrogenia. Soviet medicine. 1980; 7: 3-7 [In Russian].

Статья получена/Article received 13.03.2017 г. Принята к публикации/ Adopted for publication 03.04.2017 г. 